\title{
Results of hip resurfacing
}

\author{
Francesco Falez • Fabio Favetti • Filippo Casella • \\ Matteo Papalia • Gabriele Panegrossi
}

Received: 27 November 2010 / Accepted: 6 December 2010/Published online: 14 January 2011

(C) Springer-Verlag 2011

\begin{abstract}
Background The renewed popularity of resurfacing hip arthroplasty in the last 10 years has generated a remarkable quantity of scientific contributions based on mid- and shortterm follow-up. More than one paper has reported a consistent early revision rate as a consequence of biological or biomechanical failure. Two major complications are commonly described with resurfacing implants: avascular necrosis and femoral-neck fracture. A close relationship between these two events has been suggested, but not firmly demonstrated, whereas cementing technique seems to be better understood as potential cause of failure.

Methods We performed an in vitro study in which four different resurfacing implants were evaluated with a simulated femoral head, two types of cement, (low and high viscosity) and two cementing techniques: direct (cement apposition directly on the femoral head) and indirect (cement poured into the femoral component).

Results High-viscosity cement showed homogeneous distribution over the entire femoral head. Low-viscosity cement showed a massive polar concentration with insufficient, if not absent, distribution in the equatorial zone.

Conclusion Polar cement concentration could be a risk factor for early implant failure due to two effects on the femoral head: biological (excessive local exothermic reaction could cause osteocyte necrosis) and biomechanical (which could lead to uneven load distribution on the femoral head).
\end{abstract}

F. Falez $(\bowtie)$

Ortopedia e Traumatologia, Ospedale Santo Spirito,

Rome, Italy

e-mail: francesco.falez@francescofalez.it

F. Favetti $\cdot$ F. Casella $\cdot$ M. Papalia $\cdot$ G. Panegrossi

Orthopaedics and Traumatology, Santo Spirito in Sassia Hospital,

Rome, Italy

\section{Introduction}

Concepts in total hip replacement are significantly orientated towards conservative procedures, both for surgical approaches and implants. With regard to implants, resurfacing arthroplasty represents the most conservative solution: it carries a high potential both for joint biomechanical restoration and femoral bone preservation. This potential is extremely attractive for young and active patients. However, some concerns about short- and mid-term reliability are still debated, in particular the incidence, within the first postoperative year of avascular necrosis and femoral-neck fractures [1, 2]. Some predictive factors for implant failure have been recognised: malpositioning, surgical approach, insufficient seating of the femoral component and cementing techniques. Malpositioning of the femoral component can now be avoided by using a computer-assisted navigation system [3-5], and the use of safer surgical approaches [6] permit blood supply preservation to the proximal femur. However, the role of cement in implant failures is not yet entirely clear.

\section{Material and methods}

Our clinical experience is based on 148 consecutive resurfacing hip replacements performed between 2001 and 2010 in 146 patients. The mean follow-up period was 76 (range three to 108) months. Relative youth (range 30 60 years), high functional activity level, good bone stock and absence of morphological changes in the femoral head and neck were indications for this implant. The mean age of our patient cohort was 46.82 [minimum 30; maximum 59; standard deviation (SD) 6.44) years. The preoperative diagnosis was primary osteoarthritis of the hip in 131 hips 
(88.5\%) and post-traumatic arthritis in 17 hips (11.5\%). Avascular necrosis of the femoral head and femoral dysplasia, such as an extremely short femoral neck $(<2 \mathrm{~cm})$, were considered to be exclusion criteria. A posterolateral approach was used for all implants, and all operations were carried out by the same surgeon. Four different prostheses with different inner geometry were implanted

- BHR (Bimar/Smith \& Nephew, Verona, Italy)

- ASR (Johnson \& Johnson/Depuy, Warsaw, IN, USA)

- ReCap (Biomet, Parsippany, NJ, USA.)

- Durom (Zimmer,Warsaw, IN, USA)

(Table 1):

Two types of cement were used

- low viscosity (LV)

- high viscosity (HV)

(Table 2):

Two different cementing techniques were adopted:

- direct, with apposition of the cement directly on the femoral epiphysis;
- indirect, in which the cement is applied inside the femoral component.

Clinical evaluation based upon Harris Hip Score (HHS) [7] was carried out pre- and postoperatively (one, three and six months and each year thereafter). The results of radiological examinations (radiolucency, osteolysis, bone thickening, femoral notching) were analysed and registered on the basis of the Gruen scheme [8]. We also evaluated the distance between the stem and medial and lateral neck cortex on anteroposterior (AP) radiograms (calculated by establishing a ratio between the distance observed and the known dimension of the femoral component) and related this parameter and valgus orientation to the presence of superolateral notching. Heterotopic ossification was detected by standard methods and classified using the Brooker method [9].

\section{Results}

No patient was lost during the follow-up. Only one patient was operated upon in another institution, but the indication

Table 1 Different inner geometries of the implants

\begin{tabular}{|c|c|c|}
\hline Brand & Inner Geometry & Axial-symmetry \\
No spikes & Axial-symmetry \\
\hline BIOMET & $\begin{array}{c}\text { 2 spikes with modest range } \\
\text { DE PUY }\end{array}$ & $\begin{array}{c}\text { Non axial symmetry } \\
\text { of connection }\end{array}$ \\
\hline SMITH \& NEPHEW & of connection with modest range \\
& no spikes in other plans \\
\hline ZIMMER & Axial-symmetry \\
& of spikes with a wide range \\
\hline
\end{tabular}


Table 2 Cement features

\begin{tabular}{lll}
\hline Parameters & DePuy CMW Smartest $(\mathrm{HV})$ & Howmedica Simplex (LV) \\
\hline Liquid components & Monomer methyl methacrylate $97.5 \%(\mathrm{p} / \mathrm{p})$ & Monomer methyl methacrylate $97.4 \%(\mathrm{~g} / \mathrm{g})$ \\
& N,N-dimetil-p-toluidine $2.5 \%(\mathrm{p} / \mathrm{p})$ & $\mathrm{N}, \mathrm{N}$-dimetil-p-toluidine $2.6 \%(\mathrm{p} / \mathrm{p})$ \\
& Hydroquinone $75 \mathrm{ppm}$ & Hydroquinone $75 \pm 15 \mathrm{ppm}$ \\
Powder components & Co-polymer methyl methacrylate/methyl acrylate $84 \%(\mathrm{p} / \mathrm{p})$ & Polymethyl methacrylate $15 \%(\mathrm{~g} / \mathrm{g})$ \\
& Zirconium dioxide $15 \%(\mathrm{p} / \mathrm{p})$ & Methyl methacrylate $75 \%(\mathrm{~g} / \mathrm{g})$ \\
Viscosity & Benzoil peroxide $1 \%(\mathrm{p} / \mathrm{p})$ & Barium sulfate $10 \%(\mathrm{~g} / \mathrm{g})$ \\
Fatigue strenght $\left(10^{7}\right.$ cycles) & High & Low \\
Polymerisation temperature & $710 \mathrm{MPa}$ & $\sim 14 \mathrm{MPa}$ \\
Set time (to cement firm) at $23^{\circ} \mathrm{C}$ & $4.4 \mathrm{~min}$. & $>70^{\circ} \mathrm{C}$ \\
\hline
\end{tabular}

for a revision procedure was clearly established. The survival rate at the end point was $94.6 \%$, with eight cases revised at one and a half, four, eight and ten months postsurgery and two cases at 11, 12 and 13 months postsurgery. Indications for the revision procedure were femoral-neck fracture in five cases (Fig. 1), femoral component loosening in three (Fig. 2), painful femoral implant with incomplete radiolucency around the stem but resistance to conservative treatment (in the absence of clear radiographic signs of loosening) in one.

All failures had been performed using LV cement matched with an indirect cementing technique. Upon implant removal, all presented the same pattern of cement distribution, with a massive concentration of cement in the polar region, deep radial penetration on the head portion and complete absence of cement fixation at the head-neck junction (Fig. 3)

Histology revealed a severe and extensive necrosis at the bone-cement interface, with fibrous tissue formation at this level; in one case, fibrous tissue was significantly developed, as a possible spontaneous healing process of a femoral-neck fracture occuring underneath the implant and thus not compromising its gross stability. It was, however, responsible for persisting groin pain and evolved into a nonunion that was undetectable on X-rays and was only

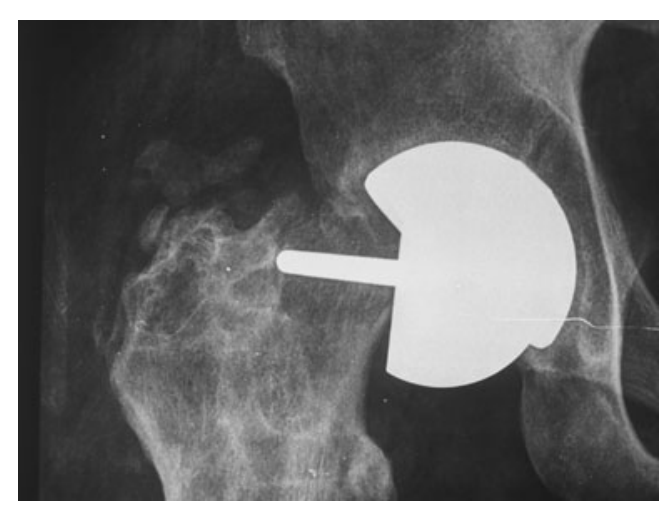

Fig. 1 Femoral-neck fracture observed at implant analysis after its removal. On the basis of these evaluations, we performed an in vitro study in which we tested the behaviour of the same types of implants used in vivo with the same type of cement and cementing techniques [10]. Each resurfacing model was implanted on four synthetic femoral heads, changing cement type (HV and LV) and cementing technique. HV cement, the technique was directly on the femoral head; for LV cement, it was indirect, inside the femoral component. The specimens were cut along two perpendicular levels, passing through the prosthesis axis, creating four identical sections in which we evaluated

- cement-occupied area (A)

- bone-cement radial penetration (P)

- diameter (D)

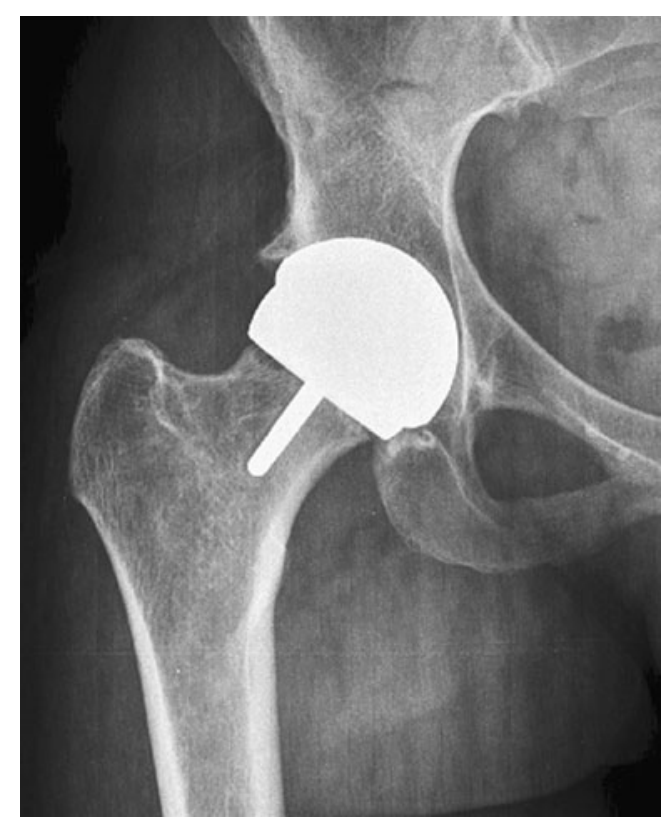

Fig. 2 Aseptic loosening of femoral component 


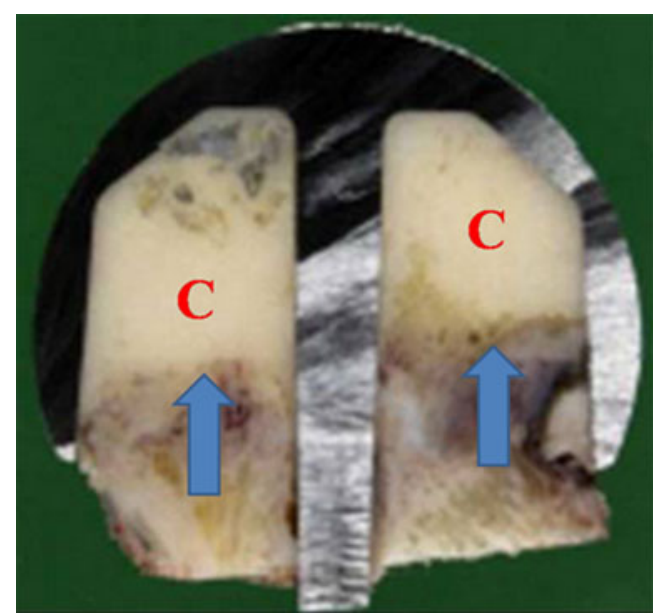

Fig. 3 In vivo failure. Low-viscosity (LV) cement matched with the indirect cementing technique was used in this case. It shows a significant concentration of cement $(C)$ in the polar region, with a deep radial penetration. Arrows show bone necrosis

(Fig. 4):

The results were comparable with the situation in vivo (Fig. 5). In the presence of LV cement (matched with indirect technique), we detected extremely high cement penetration values in the polar region in all implant designs, ranging from $4.3 \mathrm{~mm}$ to $16.6 \mathrm{~mm}$, frequently surpassing 10-mm depth (peak $16.6 \mathrm{~mm}$ for ASR implant), whereas low or absent penetration was observed in the equatorial region ranging from $0 \mathrm{~mm}$ to $2 \mathrm{~mm}$ (mean $0.5 \mathrm{~mm}$ ).

Using an HV cement matched with the direct technique, we observed a cement radial penetration between $1.85 \mathrm{~mm}$ and $5.8 \mathrm{~mm}$ (mean $4.02 \mathrm{~mm}$ ) never exceeding $6 \mathrm{~mm}$ from the polar to the equatorial region, producing a more homogeneous distribution at the bone-implant interface for each femoral design.
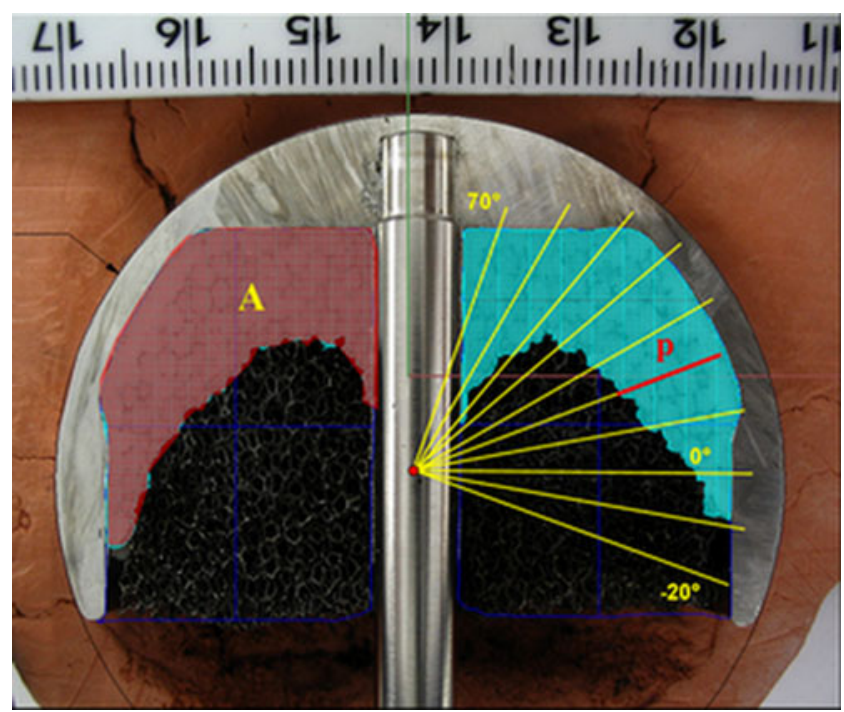

Fig. 4 Sectioned samples measuring the following: $A$ area, $P$ penetration, $D$ diameter

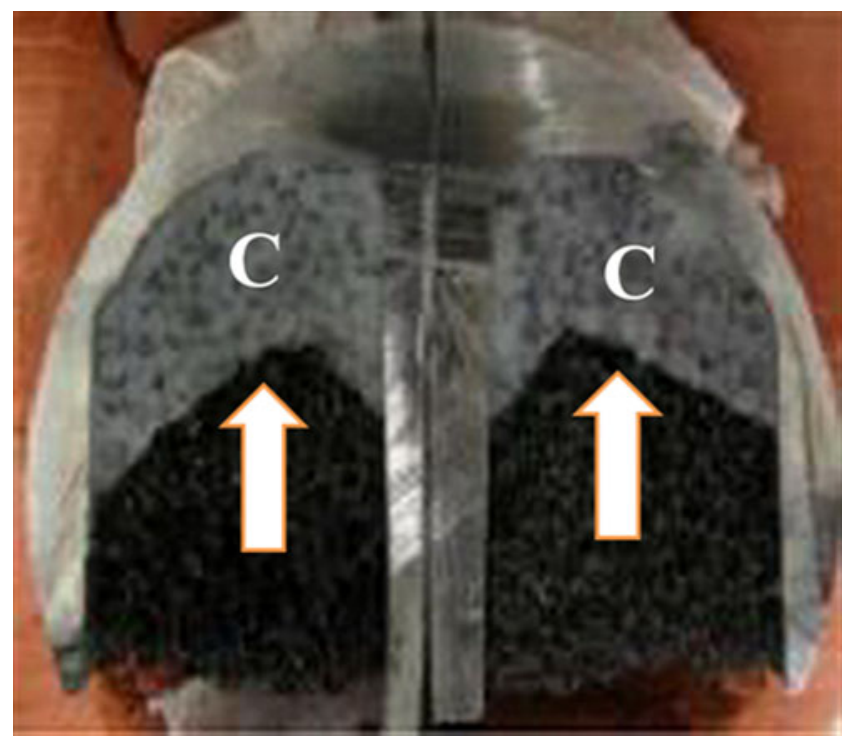

Fig. 5 In vitro result for low-viscosity cement matched with the indirect cementing technique. Massive cement $(C)$ penetration is evident in the polar region of the femoral head

\section{Discussion}

Our results demonstrate that using the same cement type (HV or LV), radial penetration was similar for all femoral components investigated; variations became marked when comparing results obtained with different cement types. According to the results of our study, LV cement applied by an indirect technique, as initially recommended by the majority of manufacturers, tended to concentrate massively in the polar region of the prepared femoral head where cement can reach as much as $16.6 \mathrm{~mm}$ of radial penetration below the surface. Conversely, there was no cement at the head-neck junction. The total area occupied with cement was $223.6 \mathrm{~mm}^{2}$. In all examined specimens with this cementing technique and a $3^{\circ}$ inner geometry divergent implant, absolutely no contact between the implant and femoral neck was identified. In contrast, when using HV cement with a direct technique, a more uniform and homogenous distribution was obtained all around the prepared femoral head. Cement penetration was not only limited to a maximum of $4 \mathrm{~mm}$ but was present at the dome of the head and at the head-neck junction, with a visible continuous bone-cement-implant interface and total area occupied by cement limited to $153.1 \mathrm{~mm}$.

Such in vitro situations if applied in vivo may represent different biological and biomechanical scenarios, providing possible explanations for both major complications occurring in resurfacing arthroplasties, such as avascular necrosis and femoral-neck fracture. Biologically deep penetration of an excessive amount of cement is responsible for a negative response in the underlying cancellous bone, with consequences 
related to the exothermic reaction of the cement, which is directly proportional to the amount of cement invading the trabecular spaces [11] and is per se responsible for cellular damage, possibly leading to implant failure. Local exothermic reaction from cement polymerisation reaches $50-53^{\circ} \mathrm{C}$ in conventional cemented implants but might increase in relation to the amount of cement up to $65^{\circ} \mathrm{C}$ in resurfacing cups, creating complete necrosis of the osteocytes [12] at the interface with penetrated cement, spreading for several millimetres in to the noninvaded trabecular bone. The whole process, as direct consequence, will bring about fibrous tissue formation at the cement-bone interface and subsequently implant micromotion or femoral-neck fracture when the inner divergent geometry of the implant creates a lack of contact with the femoral neck.

Identical findings were observed from examination of failure retrievals in our series of 148 resurfacing total hip arthroplasties performed from 2001 to 2010 using all four implants described. As mentioned, cement, rather than biological consequences, might influence the vitality of the host bone and the biomechanical performance of the implant. Predominant cement concentration over the polar region of the prepared head may be responsible for an abnormal and uneven load distribution on the femoral head [13], with a tendency to concentrate at the head-neck junction, thereby increasing the risk of neck fracture. Moreover, the amount of cement at that site will prevent the implant from seating properly on the prepared femoral head, creating two problems: (1) Incomplete seating of the resurfacing cup leaves a portion of the head-neck junction uncovered, allowing reabsorption, leading to neck narrowing or fracture due to the increased lever moment of the implant. When a divergent inner geometry implant is used, the absence of cement in this region will increase this risk of inadequate implant fit around the neck and the possibility of fluid migration at the bone-cement interface. (2) Incomplete implant seating, determined by the presence of an excessive quantity of cement, increases the joint offset and leg length.

When using HV cement with a direct technique, cement distribution patterns are similar to those shown to be the best for cemented implants: a homogenous cement mantle around the implant, with a maximum 2-3 $\mathrm{mm}$ of radial penetration in the trabecular system [14]. Direct cementing allows uniform cement distribution and allows the implant to slide on the prepared bone, removing excess cement, limiting its radial penetration and sealing the head-neck region once the implant is completely seated, thus preventing fluid migration at this level, particularly in a divergent inner-geometry implant.

In conclusion this study confirms that cement and cementing technique play significant roles in the pathogenesis of resurfacing arthroplasty failures despite bone quality and surgical technique. The amount of cement and penetration is difficult to control when positioning a resurfacing femoral cup, and achieving the most appropriate patterns of distribution should be the ultimate goal. Based on our findings, HV cement with direct application on to the femur allows the greatest possibility of controlling cement distribution around the femoral head and limiting the depth of radial penetration in the trabecular system, thus limiting possible reactive bone necrosis. We suggest this will reduce the percentage of neck narrowing related to fluid penetration at an unsealed headneck junction and thus reduce neck fracture, ultimately reducing the failure rate from bone necrosis due to excessive cement.

\section{References}

1. McMinn D, Itayem R, Arndt A, Nistor L, Lundberg A (2005) Stability of the Birmingham hip resurfacing arthroplasty at two years. J Bone Joint Surg Br 87(2):158-162

2. Amstutz HC, Campbell PA, Le Duff MJ (2004) Fracture of the neck of the femur after surface arthroplasty of the hip. J Bone Joint Surg Am 86(9):1874-1877

3. Kruger S, Zambelli P, Leyvraz PF, Jolles B (2009) Computerassisted placement technique in hip resurfacing arthroplasty: improvement in accuracy? Int Orthop 33(1):27-33

4. Schnurr C, Michael JWP, Eysel P, König DP (2009) Imageless navigation of hip resurfacing arthroplasty increases the implant accuracy. Int Orthop 33(2):365-372

5. Pitto RP, Malek S, Anderson IA (2009) Accuracy of a computerassisted navigation system in resurfacing hip artrhroplasty. Int Orthop 33(2):391-395

6. Pitto RP (2009) The trochanter slide osteotomy approach for resurfacing hip arthroplasty. Int Orthop 33(2):387-390

7. Harris H (1969) Traumatic arthritis of the hip after dislocation and acetabular fractures: treatment by mold arthroplasty. An end-result study using a new method of result evaluation. J Bone Joint Surg Am 51:737-755

8. Amstuz AC, Beaulè PE, Dorey FJ, Le Duff MJ, Campbell PA, Gruen TA (2004) Metal on metal hybrid surface arthroplasty: two to six years follow-up study. J Bone Joint Surg Am 86:28-39

9. Brooker AF, Bowermann JW, Robinson RA (1973) Ectopic ossification following total hip replacement: incidence and method of classification. J Bone Joint Surg Am 55:1629-1632

10. Falez F, Favetti F, Casella F, Papalia M, Panegrossi G (2010) Patterns of Cement Distribution in Total Hip Resurfacing Arthroplasty. J Arthroplasty (25):1162-1167

11. Campbell P, Beaulé PE, Ebramzadeh E et al (2006) The John Charnley Award: a study of implant failure in metal-on-metal surface arthroplasties. Clin Orthop Relat Res 453:35

12. Li C, Kotha S, Huang $\mathrm{CH}$ et al (2003) Finite element thermal analysis of bone cement for joint replacements. J Biomech Eng 125:315

13. Radcliffe IA, Taylor M (2007) Investigation into the affect of cementing techniques on load transfer in the resurfaced femoral head: a multi-femur finite element analysis. Clin Biomech $22: 422$

14. Star MJ, Colwell CW Jr, Kelman GJ et al (1994) Suboptimal (thin) distal cement mantle thickness as a contributory factor in total hip arthroplasty femoral component failure. A retrospective radiographic analysis favoring distal stem centralization. J Arthroplasty 9:143 